American Journal of Environmental Sciences 8 (3): 236-240, 2012

ISSN $1553-345 \mathrm{X}$

(C) 2012 Science Publications

\title{
Olive Wastewaters' Impact on Oued Boufekrane in Meknes-Tafilalet
}

\author{
${ }^{1}$ Majdouline Larif, \\ ${ }^{2}$ Abdelmajid Soulaymani, ${ }^{3}$ Mohammed Hnach and ${ }^{1}$ Azzedine Elmidaoui \\ ${ }^{1}$ Department of Chemistry, Laboratory Separation Process, \\ ${ }^{2}$ Department of Microbiology, Laboratory of Genetics and Biostatistics, \\ Faculty of Sciences, University Ibn Tofail, Kenitra, Morocco \\ ${ }^{3}$ Department of Chemistry, Laboratory Spectrometry Materials and Archaeology, \\ Faculty of Science, University Moulay Ismail, Meknes, Morocco
}

\begin{abstract}
Problem statement: Water quality of river Boufekrane is subject to heavy pollution exerted by population growth and industrial activity, including the OMW from the olive industry in which the presence of polyphenols and toxic effect dominant character may generate a higher organic pollution. Approach: Our objective is to "study the impact of OMW by analyzing the physicochemical parameters on seven sites along the bed of the Oued Boufekrane and value of Olive Mill Wastewater (OMW) polyphenols extracted as a biopesticide to contribute to environmental sustainability. Results: Results in quality that Chemical Oxygen Demand (COD), Biological Oxygen Demand $\left(\mathrm{BOD}_{5}\right)$, Total Solid (TSS) greatly exceeds the discharge standards of the WHO and the pollution of the Oued Boufekrane increases from Ain Maarouf (source control) and downstream, therefore, these waters may be used either for irrigation or for swimming. Conclusion/Recommendations: The principal component analysis allowed us to confirm the spatiotemporal correlation between physicochemical parameters and stations of the river Boufekrane. Analysis of variance of OMW polyphenols against the pest aphid (Aphis citricola) found after $24 \mathrm{~h}$ exposure by ANOVA and followed by the self test at $1 \%$ used as polyphenols, compared with controls significantly affect the survival of stages in a statistically comparable according to the concentration.
\end{abstract}

Key words: River boufekrane, olive mill wastewater, polyphenols, phytotoxicity, olive period, biopesticide

\section{INTRODUCTION}

The city of Meknes is (longitude $5^{\circ} 33$, latitude $33^{\circ} 52$ north of Morocco is an urban prefecture located on a plateau in the northwest of the Middle Atlas. In the region of Meknes Tafilalt, we focused our choice of seven resorts on the bed of the river Boufekrane because these waters are used for irrigation on large surfaces. The stations selected for the study of industrial pollution of the river bed Boufekrane are located between the resort of Ain Maarouf S1-S7 at the front end of the treatment plant Nezzala (Fig. 1). To confirm the high pollution by discharges of oil mills during the olive, the following (Fig. 1). We have found useful to study characteristic the oil mill wastewater fresh from the oil mill located in the station 5. To show the deterioration of water quality by the high toxicity of polyphenols (Bleve et al., 2011) COD, $\mathrm{BOD}_{5}$, TSS ... On the receiving environment river Boufekrane.

We have proposed a test of agricultural use to solve the environmental problem by using the polyphenols of (OMW) extracts as biopesticides against pests instead of using pesticides that are harmful to the environment point of view (Ruano et al., 2010; Kamble et al., 2012). Our goal is to follow the seasonal trend of the degree of pollution of the river Boufekrane and identify pollution stations. To do this, seven stations were selected for the study of the physical-chemical river (upstreamdownstream) of spills of industrial oil mills located upstream of the town Boufekrane and the industrial zone of Sidi Bouzekri, Olive period that begins in October and ends in January and then throughout the year (2009-2010).

Corresponding Author: Majdouline Larif, Department of Chemistry, Laboratory Separation Process, Faculty of Sciences, University Ibn Tofail, Kenitra, Morocco 


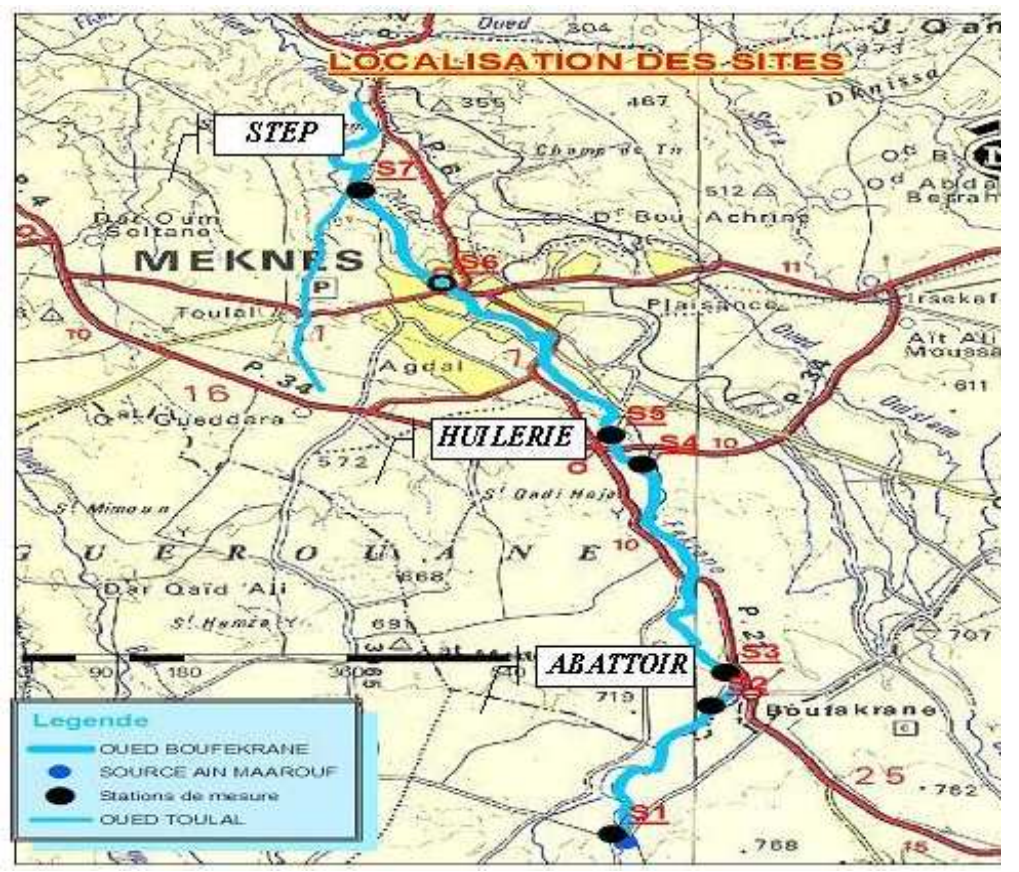

Fig. 1: Geographycal location of the study sites of the river Boufekrane

\section{MATERIALS AND METHODS}

Physico-chemical analysis of the river Boufekrane: The physicochemical analysis concerned various parameters: $\mathrm{pH}$, conductivity, (TSS) total suspended solids, $\mathrm{Cl}^{-}, \mathrm{Na}^{+}$, $\mathrm{Ca}^{2+}, \mathrm{Mg}^{2+}, \mathrm{PO}_{4}^{2-}, \mathrm{SO}_{4}^{2-}, \mathrm{NO}_{3}^{-}, \mathrm{NO}_{2}^{-},(\mathrm{OM})$ organic matter, $\mathrm{BOD}_{5}$ and $\mathrm{COD}$. The analytical methods are those recommended by the standards of AFNOR (1986). These parameters were determined following standard methods (Rodier et al., 2005). The extraction of the phenolic fraction has been carried out according to the method described by Macheix et al. (1990).

The concentration of polyphenols was carried out by a rotary evaporator set at $40^{\circ} \mathrm{C}$ and at a speed of $140 \mathrm{tr} / \mathrm{min}$.

\section{Study site of river Boufekrane:}

Origin of OMW: The fresh OMW was removed from a crushing unit system with three phases in the midst of olive cultivation. They were put in sterilized plastic containers, brought to the laboratory and kept in the dark at $4^{\circ} \mathrm{C}$ until the use by the standards of AFNOR (1986).

Insect origin: Pests of citrus green aphid (Aphis citricola) samples were collected on leaves of sour orange in the region of Meknes with the usual infestation began in early spring and then returned to the laboratory.
Biotests: Shoots of citrus branches infested by aphids (Aphis citricola) were placed inside a Petri dish $15 \mathrm{~cm}$ in diameter, the number of aphids used ranged in concentration from 101 to 311 . Thus, $87.5 \mathrm{mg}$ of polyphenols was diluted respectively in $10,20,30$ and $40 \mathrm{ml}$ of methanol at $10 \%$ to facilitate solubilization in distilled water. The concentrations tested were $0 ; 21,88$; 29,$17 ; 43,75$ to $87,5 \mathrm{mg}$ of polyphenols in $200 \mathrm{ml}$ of OMW. Aphids were then processed separately by each concentration tested.

Analysis statistical: The correlation between the physicochemical parameters of (OMW) has been studied by Principal Component Analysis (PCA) with XLSTAT 2009 software. To detect eventual significant differences between different lots tested, an analysis of variance followed by a single factor Sheffe test at the $1 \%$ was conducted on the data using SPSS software.

\section{RESULTS AND DISCUSSION}

Statistical analysis of physicochemical parameters of the river boufekrane: The statistical methodology is a descriptive analysis of the different parameters studied. The Principal Components Analysis (PCA) were also performed to detect the association between different variables and individual variables. 


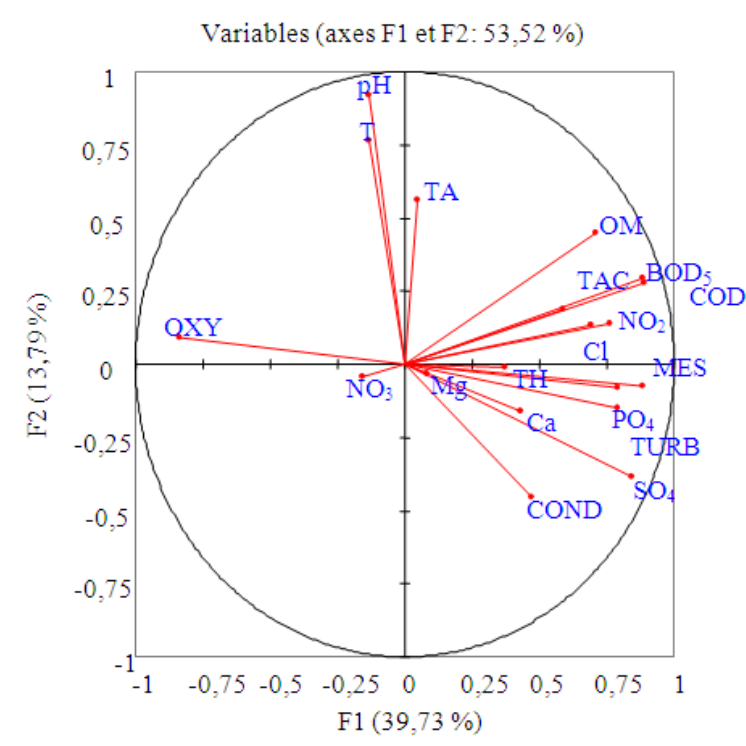

Fig. 2: Circle of correlation of physical-chemical parameters

Table 1: Mortality rates for different concentrations by ANOVA of Aphis citricola

\begin{tabular}{lllllll}
\hline C(mg/L) & Mean & $\begin{array}{l}\text { Erreur } \\
\text { standard }\end{array}$ & Min & Max & F & $\mathrm{p}$ \\
\hline Temoin & 12,22 & 2,27 & 10,56 & 14,81 & 8,681 & 0,003 \\
21,88 & 58,99 & 15,93 & 42,11 & 73,77 & & \\
29,17 & 63,01 & 29,81 & 39,53 & 96,55 & & \\
43,75 & 83,62 & 22,21 & 58,33 & 100 & & \\
87,5 & 92,71 & 6,5 & 87,5 & 100 & & \\
\hline
\end{tabular}

Circle of correlation: The correlation circle of variables (physicochemical parameters) of the river Boufekrane. The correlation circle (Fig. 2) formed by axes $\mathrm{F} 1$ and $\mathrm{F} 2$ giving $53 \%$ of the total information. The F1 axis gives $39.73 \%$, shows the alkalinity of the water after the $\mathrm{pH}$ and temperature and axis $\mathrm{F} 2$ giving $13.79 \%$ indicates the opposition between the waters polluted by nitrates and water polluted by organic matter. He defined a gradient of increasing pollution from left to right, which leads to oxygen depletion and an increase of $\mathrm{COD}, \mathrm{BOD}_{5}$ of $\mathrm{Ca}^{2+} \mathrm{Mg}^{2+}$ and nitrites, hardness, turbidity, conductivity, chlorides, sulfates, phosphates, which expresses the mineralization from left to right after (Fig. 2). This observation is coherent with the results (Ouali et al., 2009).

Cartesian diagram: Cartesian diagram showing the correlation between variables (physicochemical parameters) and individuals (stations) of the river Boufekrane.

The comments represent SiMj (station-month) with $i$ varies from 1-7 and $j$ varies from 1-12.
Based on data collected monthly principal component analysis (Fig. 3) confirms that the results are very consistent with the results obtained from the annual (Fig. 3). The plan (A) represents the period of low water level Upper diagram (Fig. 2) and (B) the lower plane of the diagram during floods.

The spatial and temporal variation confirms that during the low water level (A) upper part of the flow stream becomes weaker as the phenomenon of selfpurification is limited.

Therefore it is bound by an increase in pollution from left to right by an enrichment of the parameters indicating the quality of pollution $\mathrm{COD}, \mathrm{BOD}_{5}, \mathrm{TSS}$, MO, turbidity, conductivity, sulphates, orthophosphates, hardness, nitrite, calcium and magnesium in the stations downstream of the town Boufekrane S3 and stations downstream of Meknes in S6 and S7. It follows that (S5, $\mathrm{S} 6, \mathrm{~S} 7)>(\mathrm{S} 3, \mathrm{~S} 4)>(\mathrm{S} 2, \mathrm{~S} 1)$.

During high water part (B) rates are increased from upstream to downstream by heavy rain, stations S1-S4 the rate of nitrate is higher in winter by fertilizers leaching from soil uses farmers in the late summer and autumn. It follows that $(\mathrm{S} 1, \mathrm{~S} 2)>(\mathrm{S} 3, \mathrm{~S} 4)>(\mathrm{S} 5, \mathrm{~S} 6, \mathrm{~S} 7)$.

\section{Effect of polyphenols against pests:}

Descriptive analysis of mortality rates for different concentrations: The results of bioassays of mortality rates for different concentrations are shown in Table 1 according to the Aphis citricola by ANOVA, polyphenols of OMW extracts, the three phase system and are diluted in $10,20,30$ and $40 \mathrm{ml}$ of methanol to $10 \%$.

Analysis of variance and descriptive of Biotest: To detect eventual significant differences between different lots tested, an analysis of variance followed by a single factor test at $1 \%$ was carried out on raw data, the separate letters $(\mathrm{a}, \mathrm{b}, \mathrm{c})$ designate probability level differences to $1 \%$ according to Fig. 4 :

For P> 0.05: not significant

$0.01<\mathrm{p} \leq 0.05$ significant differences $(5 \%)$

$0.001<\mathrm{p} \leq 0.01$ : very significant difference $(1 \%)$

$\mathrm{P} \leq 0.001$ : highly significant difference $(1 \%$ )

Twenty $4 \mathrm{~h}$ after treatment, the polyphenols tested on Aphis citricola pests cause mortality and that the analysis of variance test Sheffe indicates a highly significant difference $(1 \%)$ for concentrations between $0.001<\mathrm{p} \leq 0.01$ and $\mathrm{F}=8.681>\mathrm{F}_{(0.01,4-10)}=3$. 48. In treated groups, the different concentrations of polyphenols used affect the Aphis citricola in a statistically comparable. Consequently, the as concentration is increased compared to the control reference, the mortality rate increases for Aphis citricola. 
Am. J. Environ. Sci., 8 (3): 236-240, 2012

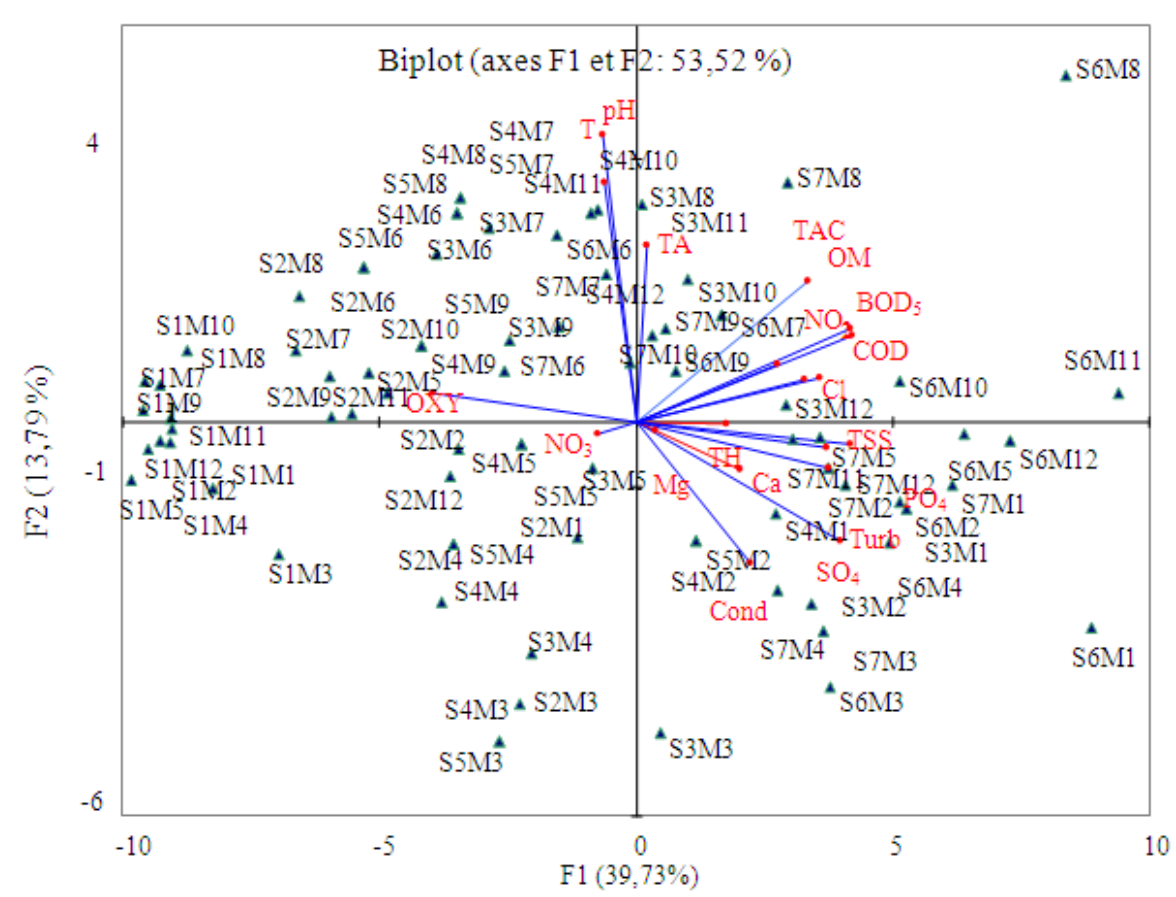

Fig. 3: Cartesian diagram showing the correlation between variables (physicochemical parameters) and individuals (stations) of the river Boufekrane

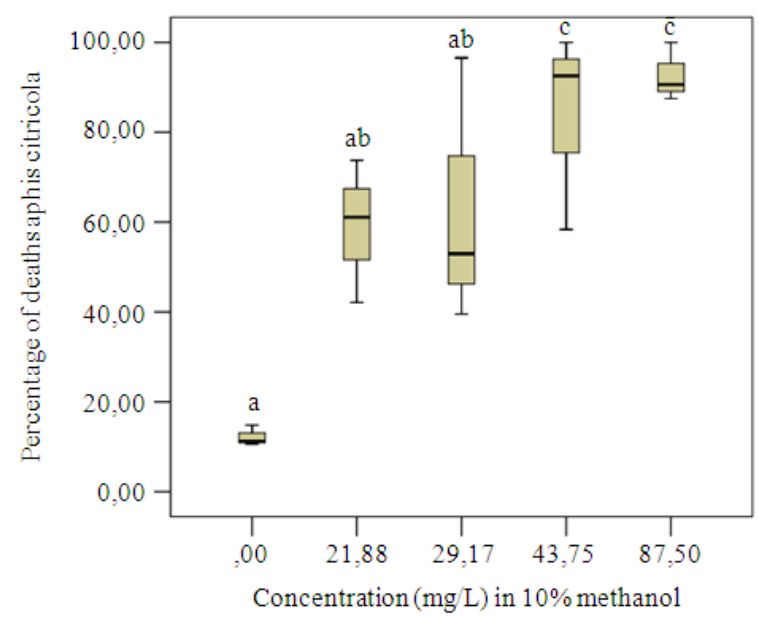

Fig. 4: Assessment by the Sheffe test AV1F rate of toxicity for the different concentrations after 24 $\mathrm{h}$ exposure

\section{CONCLUSION}

The high presence of OMW from the 3 phase system and press are responsible for high toxicity in river Boufekrane whose discharge standards are not met and constitute a health risk for people who pump for irrigation and washing vegetables at Riverside.

In terms of the fight against this pollution, efforts in cleaning devices are still absent upstream of the town of Boufekrane. To eliminate the environmental and health risks caused by the discharge of sewage in the rough environments receptors (Lake Sebou and Fouarat), it is imperative to build a wastewater treatment plant. And enforce environmental law "polluter pays". Statistically it confirms the results of the spatial and temporal variation of pollution spread over the seven stations from upstream to downstream during periods of flood and low flows. The effect of polyphenols treated with different concentrations of Aphis citricola proved satisfactory after $24 \mathrm{~h}$ of treatment and reached a mortality rate depending on different concentrations.

The recovery of polyphenols from OMW extracts as biopesticides helps protect plants against pests of citrus and simultaneously solve the environmental problem by the use of chemical insecticides.

\section{REFERENCES}

AFNOR, 1986. Eaux, Méthodes D'essai. 2nd Édn., AFNOR, Paris-La Défense, ISBN: 2121790314, pp: 624. 
Bleve, G., C. Lezzi, M.A. Chiriatti, I. D'Ostuni and M. Tristezza et al., 2011. Selection of nonconventional yeasts and their use in the immobilized form for the bioremediation of olive oil mill wastewaters. Bioresour. Technol., 102: 982-989. PMID: 20934327

Kamble, A.P., Prakash Thorat and S.W. Kulkarni, 2012. Effect of inhibitory substances on Microbiospora isolated from soil under cultivation of Curcuma longa L. Online J. Biol. Sci., 12: 1517. DOI: $10.3844 /$ ojbsci.2012.15.17

Macheix, J.J., A. Fluorite and J. Billot, 1990. Fruit Phenolics. 1st Edn., CRC Press Inc, Boca Raton Florida, ISBN: 0849349680, pp: 378.
Ouali, A., C. Azri, K. Medhioub and A. Ghrabi, 2009. Descriptive and multivariable analysis of the physico-chemicaland biological parameters of Sfax wastewater treatment plant. Desalination, 246: 496-505. DOI: 10.1016/j.desal.2008.04.058

Rodier, J., L. Bernard and M. Nicole, 2005. L'Analyse de l'eau: Eaux Naturelles, Eaux Résiduaires, Eau de Mer. Dinod, 8th Édn., Dunod, DL, Paris, ISBN: 2100496360, pp: 1383.

Ruano, F., M. Campos, A.J. Sanchez-Raya and A. Pena, 2010. Olive trees protected from the olive bark beetle, Phloeotribus scarabaeoides (Bernard 1788) (Coleoptera, Curculionidae, Scolytinae) with a pyrethroid insecticide: Effect on the insect community of the olive grove. Chemosphere, 80: 35-40. PMID: 20413141 